\title{
Das razões da indignação o insulto como estratégia política no debate parlamentar
}

\author{
Isabel Gonçalves Viola \\ Universidade Aberta, Lisboa
}

\begin{abstract}
:
This paper aims to verify how impoliteness is co-constructed in interactions within an institutional context, more specifically in the communicative situation of parliamentary debate, of an agonal nature. It is intended, therefore, to analyse the procedures that fall within the discourse register of verbal violence and in the category of insult. On the other hand, there is the purpose to study the role of emotions, namely the expression of indignation in argumentation, through the analysis of rhetorical and argumentative procedures in excerpts of controversial interactions of the political discourse subgenre in parliamentary debate, between 2009 and 2012. This analysis is part of the discourse analysis framework, particularly in the analysis of the parliamentary discourse (Ilie, 2010; Marques, 2008), specifically with regard to the "unparliamentarily language" (Ilie, 2004), and integrates theoretical contributions of the argumentation in the discourse (Amossy 2016 [2000], 2014; Plantin 2011), with particular emphasis on the emotionalization of the arguments (Micheli, 2013, 2014). This analysis will also include a number of concepts reformulated by Kerbrat-Orecchioni (1992, 1996), which concern face-work (Goffman, 1974) and face threatening acts (FTAs - Face Threatening Acts), as well as the concept of impoliteness (Culpeper 2011). The linguistic-discursive strategies used in the construction of the dissent will be analysed from a theoretical perspective of verbal violence, according to the works of Auger et al. (2008), with particular emphasis on the offensive illocutionary acts. It appears that the purpose of verbal confrontation is not to reach consensus, but rather to express disagreement and to mark a political position. Not infrequently, however, the intention of those involved in the conflictual discourse goes beyond that of refuting a contrary thesis (and demonstrating that of your party). Instead, it aims at the disqualification and ridicule of the adversary by mobilizing aggressive and destructive verbal acts, mainly associated to an escalation of emotional tension, with the purpose of building a certain political ethos (Charaudeau 2014 [2005]).
\end{abstract}

Keywords: parliamentary debate, impoliteness, insult, argumentation, emotions

Palavras-chave: debate parlamentar, impoliteness, insulto, argumentação, emoções

\section{Introdução}

Sabendo que os conflitos de opinião ocupam um espaço preponderante na cena política contemporânea, obedecendo a um princípio democrático de respeito pela diversidade e liberdade de pensamento e de expressão, o debate parlamentar apresenta-se como um lugar por excelência do aprofundamento do desacordo, sendo, por norma, os discursos modelados pela polémica e, frequentemente, dominados pelas emoções (pathos).

A nossa análise privilegia, portanto, o dissenso, enquanto luta verbal que visa aniquilar o adversário, através de uma argumentação ad passiones ${ }^{1}$. Pretende-se verificar de que forma a agressividade (the impoliteness) é coconstruída na situação comunicativa de debate parlamentar, pela análise dos procedimentos argumentativos que atualizam a violência verbal, com recurso ao insulto. Por outro lado, é nosso propósito compreender a função da argumentação das emoções, da ordem da indignação e da irritação, e verificar como o ataque ad personam constrói o ethos político dos oradores.

\footnotetext{
${ }^{1}$ Referimo-nos a uma argumentação marcada pela emoção.
} 


\section{Apresentação do corpus}

O corpus de análise, retirado do Diário da Assembleia da República² (DAR), é constituído por segmentos de dois debates parlamentares. O primeiro segmento é um pedido de esclarecimento da deputada do Bloco de Esquerda (BE), Ana Drago, ao deputado Duarte Filipe Marques (PSD), partido do governo, em coligação com o CDS-PP, e a respetiva réplica, que teve lugar na reunião plenária, de 19 de janeiro de 2012 (XII Legislatura; 1. a sessão legislativa, 2011-2012)). O segundo ocorreu durante a X legislatura (2 ${ }^{\mathrm{a}}$ sessão legislativa, 20062007), sob o governo do Partido Socialista (PS) e contempla a resposta ao pedido de esclarecimento do deputado Francisco Madeira Lopes (Os Verdes) pelo Primeiro-Ministro José Sócrates, no debate sobre o estado da Nação, de 20 de julho de 2007.

Por não serem contemplados no registo do DAR os aspetos paraverbais das sessões plenárias, a nossa análise incidirá apenas nos mecanismos linguísticos das interações parlamentares.

\section{Metodologia de análise e enquadramento teórico}

A nossa análise inscreve-se no campo da Análise do Discurso e convoca contributos teóricos interdisciplinares numa perspetiva pragmático-retórica da argumentação.

Consideraremos alguns conceitos operatórios numa perspetiva descritiva da argumentação no discurso, situando a argumentação nas interações verbais segundo os trabalhos de Amossy (2016 [2000]), Plantin (2010 [1996], 1998, 2011) e Micheli (2008, 2013, 2014), com particular relevo para a emocionalização dos argumentos. Observaremos, em primeiro lugar, a construção das emoções no discurso, pela identificação dos índices de semiotização das emoções da ordem da indignação (e da sua variante de irritação), bem como pelos princípios de relevância emocional (Ungerer, 1997) que fazem apelo ao pathos.

No plano pragmático, consideramos a noção de face (Brown \& Levinson, 1987), bem como alguns conceitos da teoria da cortesia, reformulada por Kerbrat-Orecchioni ${ }^{3}(1992,1996)$, que dizem respeito ao trabalho de figuração - face-work (Goffman, 1974) - e aos atos ameaçadores da face (FTAs - Face Threatening Acts) (Brown \& Levinson, 1987). Simetricamente oposta à teoria da cortesia, the impolitness ${ }^{4}$ apresenta-se como uma noção a privilegiar no nosso corpus de análise. Nesta perspetiva, e visto configurar uma das formas características do agravamento da face, consideraremos, no quadro psicológico da violência verbal, o ato pragmático do insulto 5 .

As razões da indignação, bem como da irritação, permitir-nos-ão perceber a função do insulto na argumentação, bem como o papel das emoções na interação e na relação pessoal. Pretendemos, por outro lado, compreender de que modo a argumentação das emoções constrói o ethos político (Charaudeau 2014 [2005]) dos oradores.

\footnotetext{
${ }^{2}$ Advirta-se que a transcrição das sessões nem sempre regista ipsis verbis os discursos espontâneos dos oradores (Marques, 2008).

${ }^{3}$ De modo lato, a noção de cortesia (que entendemos como sinónimo de delicadeza) é compreendida como todos os aspetos do discurso que são regidos por regras e cuja função é preservar o carácter harmonioso da relação interpessoal (Kerbrat-Orecchioni, 1996: 50-51).

${ }^{4}$ Ainda que não haja um modelo estável de linguistic impolitness, adotamos a definição de Culpeper: "Impoliteness is a negative attitude towards specific behaviours occurring in specific contexts. It is sustained by expectations, desires and/or beliefs about social organisation, including, in particular, how one person's or a group's identities are mediated by others in interaction. Situated behaviours are viewed negatively - considered "impolite" - when they conflict with how one expects them to be, how one wants them to be and/or how one thinks they ought to be. Such behaviours always have or are presumed to have emotional consequences for at least one participant, that is, they cause or are presumed to cause offence» (2011: 254).

${ }^{5}$ «L'insulte est un acte de langage interlocutif; elle porte une force émotionnelle, voir pulsionnelle, et vit l'autre dans la volonté de le rabaisser et de le nier. Elle tient un rôle éminemment perlocutoire («Parce que je te traite de gros lard, tu vas te sentir comme ça»). Ce fonctionnement-là est rendu possible par des effets linguistiques.» (Auger et al., 2008: 639).
} 
Finalmente, no que concerne ao discurso político, invocamos Charaudeau (2014), considerando igualmente os estudos de Ilie (2001, 2004, 2010), e de Marques (2000, 2008, 2012), no âmbito do discurso político parlamentar.

\subsection{O subgénero discursivo debate parlamentar}

Por natureza, o discurso político parlamentar é «um discurso público, de 'exercício de influência', em que os interlocutores são, por determinação da própria situação enunciativa, elementos socialmente atuantes, cidadãos detentores de um papel social especial, enquanto agentes de dinamismo e renovação social» (Marques, 2000: 58). Deste modo, os políticos vêm-se obrigados a construir uma imagem de credibilidade e competência, isto é, um ethos político positivo, de modo a legitimar o seu papel político e a permanecer no poder. A construção dessa imagem recorre a múltiplas estratégias de persuasão e de sedução, que mobilizam diversos procedimentos retóricos (Charaudeau, 2014). Afinal, não é o oponente que se pretende persuadir ou convencer, mas um terceiro, o auditório no seu sentido lato. Sublinhe-se, neste sentido, a importância da mediatização dos debates.

O debate parlamentar - genericamente descrito como uma discussão formal, sobre um tópico particular, estritamente controlada por um conjunto institucional de regras e por um moderador (Ilie, 2010) - tem uma função de fiscalização política do Governo, pelo que os partidos da oposição questionam o executivo sobre os atos da governação com o intuito de diminuir a «assimetria de informação entre o governo e a oposição»; aproveitando, por outro lado, para criticar os representantes do governo e «encenar politicamente uma posição partidária com objetivos políticos estratégicos» (Fernandes, 2015: 59). Por conseguinte, a argumentação, no debate parlamentar em particular, não tem o propósito de regular o desacordo, e sim de o radicalizar. A desvalorização e desclassificação do adversário mobiliza estratégias discursivas de cortesia negativa ${ }^{6}$ (KerbratOrecchioni, 1992) e, muitas vezes, de agressividade linguística, que configuram um desvio às normas institucionais («unparliamentary language»):

Parliamentary insults represent institutional instances of aggressive self-assertion, which imply both standing out from the group and arguing on behalf of the group. To sum up, parliamentary insulting strategies can been seen as subversive transgressions of the institutional boundaries of parliamentary language use and practises. (Ilie, 2001:259)

\subsection{A polémica no debate parlamentar}

Na perspetiva de Amossy, a polémica é entendida como uma modalidade que tem como base o conflito e as posições antagónicas: «Elle est affrontement, forte opposition de discours sur une question controversée» (2014:175). A polémica é, antes de mais, a arte da refutação, acrescenta a autora (2014:102). KerbratOrecchioni sublinha, precisamente, o pragmatismo do seu carácter refutativo:

Le discours polémique est un discours disqualifiant, c'est-à-dire qu'il attaque une cible [...], et qu'il met au service de cette visée pragmatique dominante - discréditer l'adversaire, et le discours qu'il est censé de tenir - tout arsenal de ses procédés rhétoriques et argumentatifs.» (1980:12)

A polémica no debate parlamentar distingue-se das outras interações antagonistas pela intenção pragmática dos discursos e pela especificidade do seu quadro interlocutivo. Efetivamente, o discurso polémico, determinado pelas divergências ideológicas e confronto de visões políticas, apresenta um efeito perlocutório: o

\footnotetext{
${ }^{6}$ A cortesia negativa (politesse négative) diz respeito às estratégias discursivas utilizadas para preservar a face do interlocutor, através da evitação de FTA (Face Threatening Act) ou pelo recurso a procedimentos de atenuação discursiva (Kerbrat-Orecchioni, 1992).
} 
descrédito do adversário e, inversamente, a valorização de si (ethos) e do seu partido, bem como a persuasão do auditório $\left(\right.$ pathos $^{7}$ ) para aderir ao seu ponto de vista.

A oposição de discursos supõe um contradiscurso antagonista que apresenta um duplo propósito: por um lado, a demonstração de uma tese; por outro lado, a refutação da tese adversária e a sua desclassificação (Angenot, 1982). Porém, como adverte Charaudeau, frequentemente o que está em causa não é tanto a validade das proposições do oponente, mas o descrédito da sua pessoa, no que se refere à sua moralidade, carácter ou comportamento $^{8}$ (2014), fazendo-se uso de uma argumentação ad hominem e ad personam ${ }^{9}$. Por conseguinte, a dicotomização no debate (entre o Governo e oposição) mobiliza, não raras vezes, uma argumentação agressiva, com recurso à injúria e ao insulto, que denota o envolvimento emocional dos oradores. KerbratOrecchioni refere mesmo que a polémica «s'inscrit dans un contexte de violence et passion» (1980:7), e Plantin considera que um debate pode ser legitimamente considerado uma polémica se forem percetíveis emoções da ordem da raiva e da indignação ${ }^{10}$ (2003). Amossy, por seu turno, não considera as emoções violentas como um traço definidor da polémica ${ }^{11}$; porém, ressalta o seu papel tanto na radicalização da expressão da oposição como na desvalorização do adversário (2014).

\subsection{A argumentação das emoções}

Se, por um lado, o discurso polémico revela manipulação e astúcia - procura-se suscitar o pathos no auditório de forma a conquistar a sua adesão - ; por outro lado, denota envolvimento passional e, neste sentido, revela também espontaneidade (Kerbrat-Orecchioni, 1980), surgindo o pathos como uma modalidade enunciativa do discurso. Com efeito, na argumentação ad passiones, o orador, profundamente implicado no seu propósito, exprime de forma veemente o seu sentimento no enunciado (Amossy, 2014), que revela a presença explícita do enunciador. «Au même titre que la raison, l'émotion est un produit du discours», observa Plantin (2011:2).

O choque de opiniões contraditórias é frequentemente acompanhado de emoções violentas da ordem da indignação e a irritação. Nesta ótica, Micheli (2010) considera que uma das características da polémica é a construção discursiva da emoção, defendendo que as emoções são suscetíveis de serem argumentadas, na esteira de Plantin (1998) ${ }^{12}$. Micheli (2013) propõe então um modelo de análise da «linguagem emocional», segundo uma tipologia de modos de semiotização da emoção ${ }^{13}$ : «émotion dite», «émotion montrée» e «émotion étayée».

${ }^{7}$ «Le pathos est l'effet émotionnel produit sur l'allocutaire» (Amossy, 2016:223). Advirta-se que no discurso parlamentar não é o alocutário (o adversário) que se pretende persuadir, mas um terceiro.

${ }^{8}$ Adverte Charaudeau que esse tipo de estratégia pode tornar-se numa arma «à double tranchant» [faca de dois gumes], dependendo dos limites do insulto e da valorização da polémica pelo grupo (2014: 109). Está, portanto, em causa a imagem de si que é construída no discurso.

${ }^{9}$ «Há argumentação sobre a pessoa (dita argumentação ad hominem) sempre que está em causa a verdade de uma asserção ou a legitimidade de uma conduta e, para as refutar, se faz referência a características negativas particulares da pessoa que as sustenta » (Plantin, 2010 [1996] : 87). $\mathrm{O}$ ataque ad personam, também referido por abusivo ad hominem, é simplesmente um insulto, esclarece o autor.

${ }^{10}$ Plantin lembra que a violência e a emoção se encontram noutro tipo de discursos e interação, não sendo, portanto, traços definidores da polémica (2003: 388).

${ }^{11}$ Amossy defende que polémica tem como base o conflito e as posições antagónicas, não necessariamente a violência (2014:175).

${ }^{12}$ Plantin defende a ideia de que é possível argumentar emoções, visto que os locutores procuram legitimar uma disposição afetiva quando se acham em situação de conflito ou dissenso. No quadro de uma abordagem argumentativa das emoções, na linha da tradição retórica, e considerando os contributos da Análise do Discurso e da psicologia, Plantin (1998) propõe um sistema tópico das emoções pelo meio do qual se propõe identificar o efeito de pathos visado pelo locutor. O sistema tópico, que assegura a coerência do discurso de emoção, recolhe informações sobre: o(s) tipo(s) de acontecimento(s), o tipo de pessoas afetadas, o modo de ocorrência temporal ou espacial, a distância relativamente ao locutor, o tipo de controlo exercido sobre o acontecimento em questão e a avaliação do seu impacto emocional, a classe de acontecimentos comparáveis, a maneira como as normas são afetadas pelo acontecimento.

${ }^{13}$ Micheli esclarece que o verbo semiotizar deve ser entendido no sentido de «rendre quelque chose manifeste au moyen des signes». Advirta-se também que «si on dit qu'on locuteur 'sémiotise' une émotion, on indique uniquement qu'il rend une émotion manifeste par l'usage des signes, sans présupposer qu'il éprouve effectivement cette émotion (même si cela peut bien entendu être le cas)» (2014 :18). 
A «emoção dita» manifesta-se de forma explícita no enunciado através de um termo de emoção e apresenta uma ancoragem referencial, pela presença de uma segunda expressão que designa a entidade humana que experimenta a emoção e, eventualmente, através de uma terceira expressão que designa a causa da emoção (Micheli, 2014: 23). Já os enunciados que mostram a emoção («emoção mostrada») são passíveis de uma interpretação indicial ${ }^{14}$, através de marcadores de natureza lexical, sintática e transfrásico-textual ${ }^{15}$. O terceiro tipo de semiotização, a «emoção sustentada» (tradução nossa), pressupõe a existência de uma ligação entre a experiência emocional do sujeito e a sua avaliação de uma determinada situação. Neste caso, infere-se que uma emoção fundamenta um discurso pela representação (esquematização discursiva) ${ }^{16}$ da estrutura cognitiva de uma situação, atendendo às normas socioculturais e ao quadro discursivo da enunciação: «S'il y a une situation telle que le discours la schématise, alors il y a lieu de ressentir tel type d'émotion» ${ }^{17}$ (Micheli, 2014: 29). O investigador evidencia no seu estudo que, para além dos efeitos cognitivos, as emoções estão enraizadas num conjunto de crenças e de julgamentos que as justificam (origens cognitivas), influenciando, assim, o julgamento do auditório.

$\mathrm{O}$ discurso que apela às emoções apresenta um intuito estratégico - movere - e configura-se, simultaneamente, numa estratégia de apresentação de si. Como refere Plantin, «l'ethos se construit sur l'émotion, ce qui noue solidement le lien de l'ethos au pathos» (2011: 42).

\subsection{O ethos político}

$\mathrm{Na}$ Análise do Discurso, a noção de ethos (cujo termo remonta à Retórica antiga) refere-se às modalidades verbais de apresentação de si na interação verbal e designa, nas palavras de Amossy, «l'image de soi que le locuteur construit dans son discours pour exercer une influence sur son allocutaire» (2002: 238).

Para Charaudeau, «L'ethos est affaire de croisement de regards: regard de l'autre sur celui qui parle, regarde de celui qui parle sur la façon dont il pense que l'autre le voit» (2014: 88). Nesta perspetiva, há a considerar não apenas a identidade social do locutor como também uma identidade discursiva do enunciador «qui tient aux rôles qu'il s'attribue dans son acte d'énonciation, résultat des contraintes de la situation de communication qui s'imposent à lui et des stratégies qu'il choisit de suivre» (2014: 89).

De acordo com o autor, existem duas grandes categorias de ethos, que posicionam figuras identitárias do discurso político: o ethos de credibilidade ${ }^{18}$, fundado num discurso de razão, e o ethos de identificação ${ }^{19}$, fundado num discurso de afeto.

\footnotetext{
${ }^{14}$ «Lorsqu'une émotion est montrée, l'énoncé présente un ensemble de caractéristiques qui sont susceptibles de recevoir une interprétation indicielle: l'allocutaire infère que le locuteur éprouve une émotion sur la base d'une relation de cooccurrence, voire de causalité, entre l'énonciation d'un tel énoncé, d'une part, et le fait d'éprouver une émotion, d'autre part.» (Micheli, 2014: 119).

${ }^{15}$ Para além dos marcadores lexicais (nomes, verbos, advérbios, etc) são característicos da mostração das emoções o uso das interjeições, os enunciados exclamativos e averbais, e as estruturas clivadas (marcadores sintáticos). No que respeita aos marcadores transfrásicotextuais, são frequentes procedimentos retóricos que jogam com o ritmo dos enunciados e o recurso a figuras como o paralelismo ( $c f$. Micheli, 2014).

${ }^{16}$ Com base na psicologia cognitiva (sobretudo na «Teoria da Avaliação», de Scherer [2004], citado por Micheli [2014]) e nos trabalhos de Plantin, Micheli apresenta os seguintes critérios de esquematização de uma situação potencialmente emotiva: (1) critério das pessoas implicadas (incluindo os papéis que lhes estão associados); (2) critério da distância no tempo e no espaço; (3) critério das consequências e do seu grau de probabilidade; (4) critério da atribuição causal e do agente; (5) critério do potencial de domínio [da situação]; (6) critério da semelhança (relação de analogia com outras situações pertinentes no plano emocional); (7) critério da significação normativa (verificação da compatibilidade ou incompatibilidade com os valores e normas relativamente ao grupo de referência do sujeito) (2014: 114-11).

${ }^{17}$ Ao contrário da «emoção mostrada», que apresenta um trajeto de «d'aval en amont» (Plantin, 2011: 144) - «on 'remonte' des effets de l'émotion, tels qu'ils se matérialisent dans l'énoncé, vers l'émotion supposément éprouvé par le locuteur»-, na «emoção sustentada», «le trajet interprétatif va plutôt d' 'amont en aval': on 'descend' des causes de l'émotion (une situation schématisée, c'est-à-dire, présentée sur un certain jour) vers l'émotion elle-même (à savoir l'émotion qu'il y a lieu de ressentir face à cette situation)» (Micheli, 2014:120).

${ }^{18} \mathrm{O}$ ethos de credibilidade integra o ethos de seriedade, o ethos de virtude e o ethos de competência (Charaudeau, 2014).

${ }^{19} \mathrm{O}$ ethos de identificação integra o ethos de potência, o ethos de caráter, o ethos de inteligência, o ethos de humanidade, o ethos de liderança e o ethos de solidariedade (Charaudeau, 2014).
} 
L'ethos politique est le résultat d'une alchimie complexe faite de traits de caractères personnels, de corporalité, de comportements, de déclarations verbales, cela en rapport avec les attentes floues des citoyens via des imaginaires qui attribuent des valeurs positifs ou négatifs à ces manières d'être. (Charaudeau 2014: 105)

Tal como o pathos (emoção) e o logos (razão), o ethos é um recurso estratégico à disposição do sujeito enunciador (Plantin, 2011). Na retórica argumentativa, o ethos torna-se uma categoria descritiva; se o locutor constrói uma identidade argumentativa pelo discurso, importa extrair do discurso um «retrato» do locutor: «L'être de langage 'effet du discours même' est une reconstruction d'un implicite sur la base d'indices de tous niveaux, exploitant les savoirs langagiers comme les savoirs encyclopédiques» (Plantin, 2011: 39). Segundo Plantin, a reconstrução do ethos do locutor faz-se pela exploração das inferências no suporte do discurso. Cabe ao analista escolher os seus indícios, considerando que os indícios manifestam (com um certo grau de incerteza) o ethos próprio do orador, mas também o ethos que ele deseja projetar.

\section{Das razões da indignação}

A indignação é um sentimento moral por excelência que junta o afeto e o julgamento: «[e]lle naît de la conscience d'une transgression à la règle de la justice: l'émotion y est liée à une évaluation de la situation en termes cognitifs et éthiques.» (Amossy, 2014:156). Definida como "sentimento de cólera ou de desprezo experimentado diante de indignidade, injustiça, afronta» (Dicionário Houaiss da Língua Portuguesa), a indignação manifesta-se através de vários meios linguísticos que implicam emocionalmente o sujeito de enunciação no seu enunciado, recorrendo-se a expressões que revelam subjetividade afetiva. No excerto em análise, não só são mostradas as emoções negativas da ordem da indignação como se fornece uma descrição suscetível de justificar essa emoção, ou seja, a emoção é fundamentada através da argumentação - «émotion étayée» (Micheli, 2013, 2014).

O elogio do «acordo alcançado pela concertação social» ${ }^{20}$ do deputado Duarte Filipe Marques (PSD), em declaração política no debate parlamentar, suscitou uma profunda indignação nos partidos da esquerda, designadamente, no Bloco de Esquerda (BE), tendo a deputada Ana Drago procedido a um pedido de esclarecimento (contemplado no artigo $83 .^{\circ}$ do Regimento). Criadora de polemicidade, a reação negativa ao discurso do deputado do PSD toma a forma de um contradiscurso antagonista, efetuando-se a argumentação da deputada do BE no «registo discursivo» (vd. Amossy, 2014) da violência, com recurso ao insulto - «acte de langage fondamentalement réactif, c'est-à-dire qu'elle est déclenchée par un discours (un comportement, une croyance...) à propos duquel est exprimé un désaccord» (Vincent \& Barbeau, 2012:3).

A refutação da tese do adversário faz-se por meio de uma argumentação emotiva agressiva, verificandose uma forte presença do enunciador, como se observa pela deixis pessoal e pela modalização epistémica (notese o uso do advérbio reforçador da verdade da asserção), na referência ao carácter insólito («absolutamente inarrável e pioneiro») do elogio ao acordo, que é subjetivamente avaliado como injusto (1). Este aspeto é reforçado não apenas pela deixis temporal («Até hoje»; «nunca»), como também pela repetição das construções de polaridade negativa («nenhum Deputado», «nenhuma bancada»), e ainda pelo enunciado de valor concessivo («independentemente das diferenças políticas que aqui nos dividem»), que de forma estratégica personifica a

${ }^{20}$ O Sr. Duarte Filipe Marques (PSD): - Sr. Presidente, Sr. ${ }^{\text {as }}$ e Srs. Deputados: O acordo da concertação social, esta semana alcançado, pode ter evitado uma guerra entre gerações. [...]Este acordo realiza a derradeira oportunidade e o primeiro passo para que as gerações mais velhas, em conjunto com as gerações mais novas, procurem encontrar, em conjunto, soluções equilibradas para um caminho comum que pretende alcançar um futuro sustentável para todos. [...] Durante muitos anos, os governos de vários partidos pediram empréstimos sucessivos para manter um estilo de vida acima das nossas possibilidades, ou seja, um estado de perfeita negação, como qualquer viciado. [...] Pagámos os nossos benefícios com o dinheiro dos nossos próprios filhos, sustentando o nosso vício através da penhora das gerações futuras. (DAR, XII Legislatura, reunião plenária, de 19 de janeiro de 2012) 
Das razões da indignação o insulto como estratégia política no debate parlamentar

crítica. Os procedimentos utilizados pretendem suscitar no auditório o sentimento da indignação, correspondendo ao que Ungerer (1997) designou por princípio de avaliação emocional.

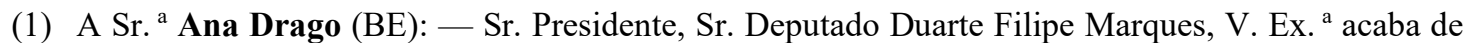
fazer um conjunto de intervenções - primeiro, na tribuna, depois, em resposta às diferentes bancadas - que eu diria ser absolutamente inarrável e pioneiro na Assembleia da República. Até hoje, eu nunca tinha ouvido nenhum Deputado, de nenhuma bancada, independentemente das diferenças políticas que aqui nos dividem, abrir uma guerra de gerações... [...] e, numa única intervenção, enxovalhar gerações e gerações de trabalhadores que trabalharam para construir este País, alguns desde os 8, 11 ou 15 anos e que ainda hoje trabalham, que deram a este País serviços públicos, segurança social, crescimento económico, desenvolvimento e democracia, que batalharam para que o Sr. Deputado tivesse a liberdade de vir a este Parlamento dizer os dislates que agora disse.

(DAR, XII Legislatura, reunião plenária, de 19 de janeiro de 2012, p.34)

A imputação da responsabilidade ao interlocutor faz-se de forma veemente ao longo de toda a intervenção, não apenas pelos procedimentos anteriormente referidos, como também pela enunciação alocutiva ( $V . E x .^{a}$ acaba de fazer um conjunto de intervenções»; «para que $o$ Sr. Deputado tivesse a liberdade de vir a este Parlamento dizer os dislates que agora disse»), e pela seleção lexical de valor axiológico negativo («enxovalhar»), que representa uma ameaça à sua face positiva (FTA) e configura um ataque ad personam («dislates»). Afinal, como afirma Micheli: «Le discours qui prétend offrir une construction argumentative de l'indignation doit ainsi se consacrer à l'identification de l'agent et à l'établissement incontestable de sa responsabilité $\left.{ }^{1}\right\rangle_{\gg}(2008: 136)$.

A argumentação apela ao pathos (pretende-se movere). O recurso ao princípio da intensidade da apresentação (Ungerer, 1997) visa criar um sentimento de empatia com os «pacientes» ( $c f$. critério das pessoas implicadas [Micheli, 2014]), apresentados como «vítimas» de um sistema que lhes impôs uma vida de sacrifício («batalharam»). Por conseguinte, a oradora mobiliza a hipérbole, através repetição do vocábulo «gerações», aludindo à sua vida de trabalho (mal remunerado, subentende-se), recorrendo a um dos tópicos desencadeadores das emoções, o da quantidade ${ }^{22}$ (Plantin, 2011:179). A forte dimensão emocional do discurso é ainda conseguida pela utilização das figuras do poliptoto (emprego de palavras flexionadas da palavra trabalhador, com a repetição das formas do verbo «trabalhar», no pretérito e no presente) — salientando-se a referência ao trabalho infantil (note-se o valor conferido pelos advérbios de predicado com valor temporal, suscitando-se o sentimento de injustiça, pelo apelo à piedade: «que ainda hoje trabalham» — e do homeoptoto (referente à semelhança produzida pelas terminações das formas verbais «trabalharam» e «batalharam»). A subsequente enumeração evidencia o contributo das «gerações de trabalhadores» para a construção do país no presente, referindo-se algumas conquistas valorizadas, em especial, pela «esquerda» («serviços públicos», «segurança social»), incluindo a democracia (alusão ao 25 de abril de 1974). Note-se como o campo lexical da democracia é continuado na palavra «liberdade» (uma conquista da democracia), que se pressupõe mal utilizada no parlamento pelo adversário («para que o Sr. Deputado tivesse a liberdade de vir a este Parlamento dizer os dislates que agora disse»).

(2) Vá dizer ao seu pai, ao seu médico, ao seu professor, [...] que a culpa da precariedade dos seus filhos e dos seus netos é deles; que foram eles, que têm $300 €$ de pensões e que trabalharam desde os 11

\footnotetext{
${ }^{21}$ «L'indignation est une émotion qui requiert que l'on dérive un état de choses négatif non comme l'effet du hasard, mais bien comme l'effet d'une action dont on peut imputer la responsabilité à un agent.» (Micheli, 2008: 136).

${ }^{22}$ Correspondente ao princípio de relevância emocional n. ${ }^{\circ 3}$, do grau e do número (Ungerer, 1997).
} 
anos de idade, que foram eles, que têm salários de $600 €$, que viveram acima das suas possibilidades!... Tenha vergonha na cara!...

(DAR, XII Legislatura, reunião plenária, de 19 de janeiro de 2012, p.34)

A crítica à tese do adversário procede numa escalada de tensão emocional (2), de acordo a regra «Montrezvous ému!» (Plantin, 2011:169), com recurso à figura de retórica da amplificação. As repetições, em enunciados clivados («que foram eles»), e exclamações mostram a indignação do locutor («emoção mostrada»), que utiliza atos diretivos sem vocativo («vá dizer»), numa clara ameaça à face negativa do interlocutor. Conquanto a enunciação seja alocutiva, é a audiência que deve ser persuadida das razões da indignação, recorde-se. Por conseguinte, a dramatização dos factos comoventes ${ }^{23}$ invoca o princípio da proximidade (Ungerer, 1997) pela referência às pessoas próximas, com utilização do deítico possessivo anteposto aos nomes («ao seu pai, ao seu médico, ao seu professor»), de forma a diminuir a distância entre as vítimas e o auditório, suscitando, assim, a empatia. Por outro lado, o recurso ao procedimento quantitativo (princípio do grau e do número [Ungerer, 1997]), através da referência aos salários e ordenados baixos, constitui um contra-argumento de incompatibilidade ao discurso prévio do adversário, colocando a ridículo a tese de que seriam essas pessoas que viviam acima das suas possibilidades as responsáveis pela crise económica do país.

A argumentação faz-se, pois, pelo viés da paixão, uma das características do discurso polémico. O ato diretivo ofensivo que consubstancia um ataque ad personam, proferido num registo inadequado à situação de formalidade requerida «Tenha vergonha na cara!...», mostra a forte indignação da oradora (ou mesmo a sua aversão relativamente ao adversário), justificada pelo que é apercebido como uma violação da regra da justiça ${ }^{24}$.

Observa Plantin que «les émotions sont fondamentalement marquées par la division des valeurs et des intérêts.» (2011: 181). A razão de protestar com violência decorre, pois, da avaliação de uma situação negativa - o ultraje feito às gerações mais velhas (que, após uma vida de trabalho, veem os direitos adquiridos serem levianamente retirados) -, construindo-se assim um ethos de solidariedade, inverso à imagem negativa que se constrói do adversário, pela acusação implícita de falta de empatia, sensibilidade, e mesmo desprezo pelo sacrifício das pessoas «que [tanto] deram [ao] País». Através da figura do vitupério ${ }^{25}$, a oradora consolida o seu ethos prévio de combatividade e constrói um ethos de carácter, de quem não se conforma com o atual estado de coisas (cf. Charaudeau, 2014), em consonância com o posicionamento ideológico do seu partido.

As razões da indignação são argumentadas através da esquematização discursiva da «emoção sustentada» (Micheli, 2014), que explora os seguintes critérios: 1) das pessoas implicadas («gerações e gerações de trabalhadores»; «Vá dizer ao seu pai, ao seu médico, ao seu professor»); 2) da distância no tempo e no espaço («V. Ex. ${ }^{\mathrm{a}}$ acaba de fazer um conjunto de intervenções [...] Até hoje, eu nunca tinha ouvido [...] na Assembleia da República. »; «este País»), verificando-se também a proximidade das pessoas implicadas («Vá dizer ao seu pai, ao seu médico, ao seu professor»); 4) atribuição causal e do agente ( $V$. Ex. ${ }^{a}$ acaba de fazer um conjunto de intervenções [...] abrir uma guerra de gerações [...] enxovalhar gerações e gerações de trabalhadores [...]»); 5) potencial de domínio ou controlo da dimensão («Os senhores só prometem aos jovens um futuro pior») (3);

\footnotetext{
${ }^{23}$ A emoção é comunicada. Os procedimentos discursivos utilizados na dramatização dos factos funcionam como panthèmes — «des éléments cencés provoquer une émotion dans l'auditoire» (Amossy, 2016 :231).

${ }^{24}$ «[l'] orientation émotionnelle vers le domaine de la rage et de l'indignation est produite par la construction argumentative-affective des différents éléments de la situation: de quoi s'agit-il? Quelles sont les possibilités de contrôle? Cette rage est construite, incrustée dans le formatage de l'évènement rapporté comme un déni de justice, dont les responsables sont connus et contre qui on ne peut rien» (Plantin, 2011:201).

25 «[... la vitupération qui blâme, critique et s'indigne en s'exprimant par 'coups de gueule'[...] témoigne d'une indignation qui a besoin d'être exprimé avec force» (Charaudeau, 2014: 107).
} 
Das razões da indignação o insulto como estratégia política no debate parlamentar

7) significação normativa ${ }^{26}$, ligada à perceção que o agente não atua segundo as normas esperadas («V.Ex. ${ }^{a}$ acaba de fazer um conjunto de intervenções [...] que eu diria ser absolutamente inarrável [...]»), causando danos a terceiros (às gerações mais velhas). Sublinhe-se que os valores variam consoante o grupo de referência do sujeito; neste caso, trata-se dos valores de solidariedade social defendidos, particularmente, pelo BE. Note-se, porém, que a oradora sublinha que nunca «nenhum Deputado, de nenhuma bancada» tinha feito um discurso daquele teor, o que particulariza a ofensa.

(3) [...] Não, Sr. Deputado! Os senhores só prometem aos jovens um futuro pior, e por isso é que o Governo disse aos jovens deste País: «Emigrem!» Mas tenho uma outra coisa para lhe dizer, Sr. Deputado: por favor, emigre!! [...]

(DAR, XII Legislatura, reunião plenária, de 19 de janeiro de 2012, p.34)

O uso do advérbio de negação (3) («Não, Sr. Deputado!») marca uma viragem na argumentação, sendo o alvo da crítica generalizado ao partido do governo (PSD), como se verifica pela enunciação alocutiva («Os senhores só prometem aos jovens um futuro pior»). A contra-argumentação da tese do adversário faz-se com recurso à polifonia - «l'énoncé dialogique peut tout à fait faire entendre un autre énoncé qu'il conteste.» (Bellemmouche, Baklouti \& Alokla, 2016:6). O conteúdo proposicional da citação (pela alusão abusiva a enunciados do Governo que causaram polémica ${ }^{27}$ ) é objeto de uma reorientação argumentativa, tomando então como alvo o interlocutor (4). Exibindo uma forte implicação no seu enunciado («Mas tenho uma outra coisa para lhe dizer»), a locutora, já numa enunciação alocutiva, profere o ato performativo primário «Sr. Deputado: por favor, emigre!!», que apresenta um duplo sentido de exclusão e configura um abuso verbal (impoliteness) $)^{28}$. Deste modo, a oradora não constrói apenas um ethos de agressividade, mas também de arrogância.

(4) O Sr. Presidente (Ferro Rodrigues): - Sr. a Deputada, tem mesmo de terminar.

A Sr. ${ }^{a}$ Ana Drago (BE): - Termino já, Sr. Presidente. Sr. Deputado, estou a olhar para si e estou pasmada com a plástica que o senhor tem, porque o senhor é velho, velho, velho, velho dos tempos da União Nacional!! [...]

(DAR, XII Legislatura, reunião plenária, de 19 de janeiro de 2012, p.35)

A emoção autoatribuída num registo irónico («estou pasmada») (4) agudiza a crítica que se faz através de um ataque ad personam, recorrendo-se ao insulto ${ }^{29}$. O ataque é intensificado quer pela metáfora da «plástica» quer pelas figuras da epizeuxe (repetição) e da hipérbole. Note-se a seleção do adjetivo "velho», atributo de qualidades físicas, para evidenciar os valores antiquados e conservadores do adversário (« [...] dos tempos da União Nacional!! ») $)^{30}$.

\footnotetext{
${ }^{26}$ Como referem Ambroise-Rendu e Delphore (citados por Micheli, 2014: 127), a indignação «ne met pas en jeu la seule conscience individuelle, mais bien des valeurs et repères collectifs [...]. Elle a donc une valeur normative, en ce sens qu'il n'y a pas d'indignation sans affirmation explicite ou implicite d'une norme du tolérable, du juste».

${ }^{27}$ «Se estamos no desemprego, temos de sair da zona de conforto e ir para além das nossas fronteiras» (Alexandre Miguel Mestre, secretário de Estado da Juventude e do Desporto, outubro de 2011). Também o chefe do governo, numa entrevista ao Correio da Manhã, propusera a emigração como solução para o problema dos professores excedentários: "Em Angola e não só. O Brasil tem também uma grande necessidade ao nível do ensino básico e secundário" (Pedro Passos Coelho, Primeiro-Ministro, 18 de outubro de 2011).

${ }^{28} \mathrm{O}$ ato proferido é, segundo Culpeper, um dos atos que configuram the impolitness (dimissals) (2010:3243), que compreendemos como uma subcategoria da agressão verbal.

${ }^{29} \mathrm{O}$ insulto revela «falta de respeito, desprezo, por outro ou por suas crenças»; «ação ou resultado dela que deixa transparecer aversão ou menosprezo pelos valores, pela capacidade, inteligência ou direito dos demais» (Dicionário Houaiss da Língua Portuguesa).

30 «União Nacional» designa a organização política portuguesa criada para apoio ao Estado Novo, que tinha como presidente António de Oliveira Salazar e defendia como ideologia o nacionalismo português e o conservadorismo social.
} 
O facto de a oradora expressar com força a sua indignação, de se mostrar estupefacta e escandalizada, obedece a uma estratégia política: suscitar emoções no auditório pela dramatização do seu discurso é predispôlo a aderir às ideias que se defende (Charaudeau, 2014:159). O insulto cumpre a função de enfraquecer a imagem política do adversário, apresentando-o sob a forma de estereótipo com atributos detestáveis ou indesejáveis:

Parliamentary insults are offensive rhetorical acts performed in a highly competitive institutional setting. They are deliberate in the sense that they are intended to be perceived and recognised as such by the person targeted. Unparliamentary language uses can provide important clues about moral and social standards, prejudices, taboos, as well as value judgements of different social and political groups and individuals in a community. Because they underlie culturally defined negative values and norms, insults are meant to reduce the targeted person, group or institution (and what they stand for) to stereotypically undesirable or detestable attributes. (Ilie, 2004: 53)

Por seu turno, o deputado do PSD mostra-se indignado pela ofensa (5) e refuta de forma assertiva as acusações, mantendo-se num registo adequado ao quadro institucional, renunciando à polémica. $\mathrm{O}$ orador procura reparar a sua imagem pela construção de um ethos de solidariedade e de convicção. A crítica à interlocutora faz-se de uma forma indireta, através da asserção de polaridade negativa, distanciando-se de uma atitude «demagógica».

(5) O Sr. Duarte Filipe Marques (PSD): - Sr. ${ }^{a}$ Deputada, há coisa que não lhe admito: que me julgue dessa forma.

A Sr.a Ana Drago (BE): — Então, não diga o que diz! [...]

O Sr. Duarte Filipe Marques (PSD): - Eu estive lá fora a lutar pelos jovens [...] eu estarei sempre ao lado dos jovens, porque acredito que as soluções que defendo são o melhor para eles! $\mathrm{Sr}^{\text {a }}$ Deputada, não faço política com demagogia,...

(DAR, XII Legislatura, reunião plenária, de 19 de janeiro de 2012, p.35)

\subsection{Da indignação à irritação}

Se a argumentação ad passiones corresponde a uma estratégia de persuasão do auditório para aderir a uma imagem desvalorizante do deputado do Governo, de acordo com o papel de vigilância da ação governativa por parte da oposição, já a argumentação da indignação por parte de quem detém o poder cumpre outra função.

Besides that, the deepening of disagreement, also envisaged by the debates, enables an aggressive interpersonal relation and, as a consequence, the manifestation of another type of emotion, irritation. In fact, these are regulated and controlled emotions that are part of political game. (Marques, 2012:121)

Efetivamente, na sua resposta ao pedido de esclarecimento do deputado Francisco Madeira Lopes (Os Verdes), o Primeiro-Ministro José Sócrates justifica sua indignação pelo facto de o Partido Comunista (PCP) e de os Verdes (PEV) não reconheceram («não encontro explicação») as políticas de combate às alterações climáticas na agenda do Governo (6). A refutação das críticas acusa a impaciência do orador, que recorre à modalidade polémica para desclassificar os adversários, pela sua atitude de permanente combate político. A emoção é mostrada pela seleção de léxico pejorativo em enunciados exclamativos. Note-se a intensificação da emoção através das asserções epistemicamente modalizadas: primeiro, o orador apresenta um menor grau de certeza relativamente ao conteúdo expresso («Penso que vai nisso uma cegueira sectária [...]»); no enunciado 
subsequente, o orador assume claramente o seu conteúdo proposicional através do uso da locução adverbial reforçadora da verdade da asserção ( «De facto, essa postura transforma e obnubila o vosso pensamento!»).

O aumento de tensão emocional decorre da provocação dos deputados do PCP (partido que integra a coligação CDU com o PEV), que, em sucessivas intervenções não autorizadas (apartes) (6), conseguem desestabilizar e destruir o seu discurso. Note-se, no primeiro aparte do deputado João Oliveira, a alusão irónica à «cassete» (denominação recorrentemente utilizada pelo PS para qualificar o discurso repetitivo do PCP), como réplica à expressão «cegueira sectária», solidarizando-se, assim, de forma irónica, o deputado do PCP com o Primeiro-Ministro.

(6) O Sr. Primeiro-Ministro: - Sr. Presidente, Srs. Deputados, Sr. Deputado Francisco Madeira Lopes, há 30 anos que o Partido Comunista e que Os Verdes

O Sr. António Filipe (PCP): - Há 30 anos Os Verdes ainda não existiam!

O Orador: - acusam o Partido Socialista, quando está no Governo, de ser de direita e de desenvolver políticas de direita. Penso que vai nisso uma cegueira sectária para a qual, por vezes, não encontro explicação!

O Sr. João Oliveira (PCP): - É sempre a mesma «cassete»!

O Orador: - De facto, essa postura transforma e obnubila o vosso pensamento! No meu discurso, falei [...] na prioridade que a Presidência portuguesa sempre atribuiu ao plano tecnológico para a energia e o Sr. Deputado devia saber que, hoje, a palavra-chave para inovação, tecnologia e energia é a das alterações climáticas, que sempre estiveram no programa da Presidência.

O Sr. João Oliveira (PCP): - Alterações climáticas são duas palavras e não uma palavra-chave!

(DAR; X Legislatura, reunião plenária, de 20 de julho de 2007, pp. 35-36)

A atitude provocatória dos deputados da CDU converte-se em estímulo de um outro estado emocional mais intenso. A indignação do Primeiro-Ministro dá lugar à irritação ${ }^{31}$, o que o faz entrar em diálogo direto com o deputado do PEV e mobilizar um ataque pessoal (7). O orador utiliza como estratégia de mitigação o procedimento que Ilie designa por «attribution transfer» ${ }^{32}$ (2004: 59) - «acusações ridículas» - sob a forma de ato diretivo de polaridade negativa (que agrava a ofensa). A justificação da qualificação pejorativa dos argumentos do adversário faz-se pela sua repetição, recorrendo-se, porém, à enunciação delocutiva, com valor de evidência. Repare-se como o argumento causal contempla um apelo ad populum («toda a gente sabe»), fazendo-se uso da doxa, com o intuito de reforçar a justeza da crítica feita ao adversário. A interrupção do deputado do PEV, que implicita a acusação de incompetência do Governo, provoca um aumento de tensão emocional que culmina no insulto proferido pelo orador: «Sr. Deputado, eu não tenho culpa da sua ignorância»,

(7) O Sr. Francisco Madeira Lopes (Os Verdes): — E o que é que os senhores estão a fazer? Nada! O Orador: - Sr. Deputado, não faça acusações ridículas! Isso é uma acusação ridícula, porque toda a gente sabe que para a Presidência portuguesa e para toda a Europa é absolutamente indispensável manter o tópico das alterações climáticas no topo da agenda. Porquê? Porque Portugal é um dos países que mais pode mostrar serviço nesse domínio.

\footnotetext{
${ }^{31}$ Definida como «exaltação facilmente provocável, estado de nervosismo ou cólera contida; [...] exacerbação, exasperação» (Dicionário Houaiss da Língua Portuguesa).

32 "A mitigation strategy [...] is what I propose to call the attribution transfer strategy. It consists in the speaker's making use of indirect attribution strategies in order to avoid taking direct responsibility for using derogatory qualifiers to characterize someone» (2004: 59).
} 
O Sr. Francisco Madeira Lopes (Os Verdes): - Pudera! Era o que estava mais atrasado!

O Orador: - Sr. Deputado, eu não tenho culpa da sua ignorância!

(DAR; X Legislatura, reunião plenária, de 20 de julho de 2007, pp. 35-36)

A dimensão de confronto é intensificada pela coconstrução da agressividade na interação, que se manifesta pelo aumento de tensão emocional do orador, em reação às constantes provocações dos adversários, apresentando, por conseguinte, um ethos fortemente emocional que favorece a mobilização de ataques ad personam. $\mathrm{O}$ insulto configura-se numa estratégia de contra-ataque e apresenta, essencialmente, uma função refutativa. Para além do ethos agressivo, o insulto constrói um ethos de arrogância.

\section{Considerações finais}

Os discursos analisados são marcados pela modalidade polémica e pelo forte envolvimento emocional dos oradores, recorrendo-se a uma argumentação veemente da ordem do ethos e do pathos. A exploração argumentativa das emoções visa, sobretudo, a descredibilização da posição do adversário e a valorização do seu ethos político.

A comunicação das emoções, com apelo ao pathos, está ao serviço da dramatização do discurso e obedece a uma estratégia política de persuasão do auditório com vista à adesão do ponto de vista do orador. No primeiro excerto, a indignação surge como um sentimento ligado à avaliação de uma situação injusta, fazendo-se apelo aos valores. Procura-se construir um ethos solidário e, simultaneamente, consolidar a identidade política do BE pelo desacordo com as políticas do Governo. A emoção é argumentada, fundamentando-se as razões que a justificam («emoção sustentada»), com base em critérios específicos que têm em vista orientar o auditório a experimentar determinada emoção. A forte implicação do sujeito no seu discurso é igualmente percetível através da «emoção mostrada», pela interpretação dos índices semióticos emocionais. A argumentação ad passiones mobiliza a figura do vitupério, que demonstra um ethos de contestação e também de carácter, e recorre a ataques pessoais, construindo-se um ethos político agressivo. Por sua vez, a «emoção dita» visa agravar o ataque ao oponente. $\mathrm{O}$ insulto é a principal estratégia de desqualificação do adversário e de destruição do seu discurso. Configura-se como um instrumento de contrapoder e contribui para uma imagem de arrogância da deputada do BE.

No segundo excerto analisado, a emergência do estado emocional do orador decorre de uma relação interpessoal agressiva, apresentando ethos marcadamente emocional e agressivo. O aumento de tensão revelase pela forte implicação do sujeito no seu discurso e pelos ataques do domínio do ethos ao adversário, o que atesta, por outro lado, o alto grau de competitividade política no parlamento. O insulto surge como manifestação do estado emocional de irritação e apresenta uma função refutativa. É também uma manifestação de poder.

\section{Referências:}

Amossy, Ruth (2002) Ethos. In Patrick Charaudeau et Dominique Maingueneau (dir.) Dictionnaire d'Analyse $d u$ Discours. Paris: Seuil, pp. 238-240.

Amossy, Ruth (2014) Apologie de la polémique. Paris: Presses Universitaires de France.

Amossy, Ruth (2016 [2000]) L'argumentation dans le discours. Paris: Armand Colin.

Angenot, Marc (1982) La Parole pamphlétaire: contribution à la typologie des discours modernes. Payot: Paris. Auger, Nathalie, Béatrice, Fracchiola, Claudine Moïse \& Christina Schultz-Romain (2008) De la violence verbale pour une sociolinguistique des discours et des interactions. Actes du Congrès Mondial de Linguistique Française. Paris: EDP Sciences, pp. 631-643. 
Bellemmouche, Hacene, Elodie, Baklouti \& Abdelrhamn Alokla (2016) Manifestations discursives du désaccord en domaine français. Cahiers de praxématique (67). [En ligne] (consulté le 13 septembre 2019) DOI: https://doi.org/10.4000/praxematique.4346

Brown, Penelope \& Stephen Levinson (1987) Politeness: Some universals in language use. Cambridge: Cambridge University Press.

Charaudeau, Patrick (2014 [2005]) Le discours politique: les masques du pouvoir. Limoges: Éditions Lambert-Lucas. Culpeper, Jonathan. (2010) Conventionalised impoliteness formulae. Journal of Pragmatics 42 (12), pp. 3232-3245. Culpeper, Jonathan (2011) Impoliteness: Using language to cause offence. Cambridge: Cambridge University Press.

Diário da Assembleia da República (DAR). Disponível em: https://www.parlamento.pt/DAR/ Paginas/default.aspx

Dicionário Houaiss da língua portuguesa (2003) Lisboa: Temas e Debates.

Fernandes, Jorge (2015) O Parlamento português. Lisboa: Fundação Francisco Manuel dos Santos.

Goffman, Erving (1974) Les Rites d'interaction. Paris: Minuit.

Ilie, Cornelia (2001) Unparliamentary language: Insults as cognitive forms of ideological confrontation. In René Dirven, Roslyn Frank and Cornelia Ilie (eds.) Language and ideology, Vol. II: Descriptive cognitive approaches. Amsterdam/ Philadelphia: John Benjamins, pp. 235-263.

Ilie, Cornelia (2004) Insulting as (un)parliamentary practice in the British and Swedish Parliaments: A rhetorical approach. In Paul Bayley (ed.) Cross-Cultural Perspectives on Parliamentary Discourse. Amsterdam: John Benjamins, pp. 45-86.

Ilie, Cornelia (ed.) (2010) European parliaments under scrutiny: Discourse strategies and interaction practices (Vol. 38). Amsterdam: John Benjamins Publishing.

Kerbrat-Orecchioni, Catherine (1980) La polémique et ses définitions. Le discours polémique. Lyon: Presses Universitaires de Lyon, pp. 3-40.

Kerbrat-Orecchioni, Catherine (1992) Les Interactions Verbales, tome II. Paris: Armand Colin.

Kerbrat-Orecchioni, Catherine (1996) La conversation. Paris: Mémo Seuil.

Marques, Maria Aldina (2000) Funcionamento do discurso político parlamentar: a organização enunciativa no debate da interpelação ao governo. Braga: CEHUM - Universidade do Minho.

Marques, Maria Aldina. (2008) Arrogância e construção do ethos no discurso político português. Atas do III Simpósio Internacional Sobre Análise do Discurso. Belo Horizonte: UFMG, pp. 1-10.

Marques, Maria Aldina (2012) Emotions and Argumentation in the Portuguese Parliament. In Liliana IonescuRuxăndoiu (ed.) Parliamentary discourses across cultures: Interdisciplinary approaches. New Castle : Cambridge Scholars Publishing, pp. 117-131.

Micheli, Raphaël (2008) La construction argumentative des émotions: pitié et indignation dans le débat parlementaire de 1908 sur l'abolition de la peine de mort. In Michael Rinn (ed.) Emotions et discours. L'usage des passions dans la langue. Rennes: Presses Universitaires de Rennes, pp. 127-141.

Micheli, Raphaël (2010) Qu'est-ce qu'une polémique affective? Réflexion sur les liens entre la polémique et la construction discursive de l'émotion. In Luce Albert et Loïc Nicolas (éd.) Polémique et rhétorique, coll. Champs linguistiques. Bruxelles : De Boeck, pp. 351-362.

Micheli, Raphaël (2013) Esquisse d'une typologie des différents modes de sémiotisation verbale de l'émotion. Semen, Revue de sémio-linguistique des textes et discours (35). [en ligne] (consulté le 11 avril 2018) DOI : https://doi.org/10.4000/semen.9795

Micheli, Raphaël (2014) Les émotions dans les discours: modèle d'analyse et perspectives empiriques. Bruxelles: De Boeck.

Plantin, Christian (1998) Les raisons des émotions. In Marina Bondi (ed.) Forms of argumentative discourse / Per un'analisi linguistica dell'argomentare. Bologne: CLUEB, pp. 3-50. 
Plantin, Christian (2003) Des polémistes aux polémiqueurs. In Gilles Declercq, Michel Murat et Jacqueline Dangel (éds.) La parole polémique. Paris: Champion, pp. 377- 408.

Plantin, Christian (2010 [1996]) A argumentação, trad. Rui Grácio e Martina Matozzi. Coimbra: Grácio Editor. Plantin, Christian (2011) Les bonnes raisons des émotions. Principes et méthode pour l'étude du discours émotionné. Berne: Peter Lang.

Ungerer, Friedrich (1997) Emotions and emotional language. In S. Niemeier and R. Dirven (eds) The language of emotions. Amsterdam/ Philadelphia: John Benjamins.

Vincent, Diane \& Geneviève Barbeau (2012) Insulte, disqualification, persuasion et tropes communicationnels: à qui l'insulte profite-t-elle?. Argumentation et analyse du discours, (8). [en ligne] (consulté le 5 septembre 2019) DOI : https://doi.org/10.4000/aad.1252 